\title{
Pharmacokinetics of a Novel Orodispersible Tablet of Amlodipine in Healthy Subjects
}

\author{
Vincent Mascoli*, Uma Kuruganti ${ }^{2}$, Akula Thukaram Bapuji ${ }^{3}$, Rong Wang ${ }^{2}$ and Bharat Damle ${ }^{1}$ \\ ${ }^{1}$ Pfizer Inc., 235 East 42nd Street, New York, NY 10017, USA \\ ${ }^{2}$ Pfizer Inc., 445 Eastern Point Road, Groton, CT 06340, USA \\ ${ }^{3}$ Aurobindo Pharma Ltd., Plot \# 2, Maitri Vihar, Ameerpet, Hyderabad 500 038, Andhra Pradesh, India
}

\begin{abstract}
Purpose: An orally disintegrating tablet (ODT) of amlodipine has been developed for the benefit of patients who have difficulty swallowing solid dosage forms.

Methods: Two pivotal bioequivalence studies of amlodipine ODT given with and without water, versus either amlodipine tablets or capsules, were conducted in 36 subjects each. Both studies were randomized, open-label, crossover, single-dose $(10 \mathrm{mg})$ studies in healthy subjects ages 18 to 55 years. Plasma samples were collected for 168 hours post dose and pharmacokinetics were determined by non-compartmental analyses.

Results: Amlodipine ODT with or without water was bioequivalent to amlodipine tablets as the ratio $(90 \%$ $\mathrm{Cl}$ ) of $\mathrm{C}_{\max }, \mathrm{AUC}_{\infty}$, and $\mathrm{AUC}_{\text {last }}$ were contained within $80-125 \%$. Amlodipine ODT with or without water was also bioequivalent to amlodipine capsules as the ratio $(90 \% \mathrm{Cl})$ of $\mathrm{C}_{\max }, \mathrm{AUC}_{\infty}$, and $\mathrm{AUC}_{\text {last }}$ were contained within 80 $125 \%$.

Conclusion: Amlodipine ODT, given with or without water, provides equivalent systemic exposure compared to amlodipine tablets or capsules.
\end{abstract}

Keywords: Amlodipine; Orodispersible tablet; Pharmacokinetics

Abbreviations: $\mathrm{AUC}_{\text {last }}$ : Area Under the Concentration Versus Time Curve to the Last Quantifiable Time Point; AUC : Area Under the Concentration Versus Time Curve from Time 0 Extrapolated to Infinite; AE: Adverse Event; BMI: Body Mass Index; CI: Confidence Interval; $\mathrm{C}_{\max }$ : Maximum Plasma Concentration; ECG: Electrocardiogram; K2-EDTA: Dipotassium Ethylene Diamine Tetraacetic Acid; $\lambda z$ : Elimination Rate Constant; ODT: Orally Disintegrating Tablet; $\mathrm{T}_{\max }$ : Time for $\mathrm{C}_{\max }$; K2-EDTA: Dipotassium Ethylene Diamine Tetraacetic Acid

\section{Introduction}

Amlodipine is a calcium ion influx inhibitor of the dihydropyridine group (slow channel blocker or calcium ion antagonist) which inhibits the transmembrane influx of calcium ions into cardiac and vascular smooth muscle [1]. Amlodipine has several indications including first-line treatment of hypertension, to reduce the risk of coronary revascularization and the need for hospitalization due to angina pectoris, and first-line treatment of myocardial ischemia. Amlodipine tablets and capsules are available in strengths of 5 and $10 \mathrm{mg}$. For both hypertension and angina, the usual initial dose is amlodipine $5 \mathrm{mg}$ once daily which may be increased to a maximum of $10 \mathrm{mg}$ depending on the individual patient's response.

After oral administration of therapeutic doses, amlodipine is well absorbed with peak blood levels occurring between 6 and12 hours post-dose. Absolute bioavailability has been estimated to be between $64 \%$ and $80 \%$, and the volume of distribution is approximately $21 \mathrm{~L} / \mathrm{kg}$. Absorption of amlodipine is unaffected by consumption of food [2-4]. In vitro studies have shown that approximately $97.5 \%$ of circulating amlodipine is bound to plasma proteins [2].

The terminal plasma elimination half-life $\left(t_{1 / 2}\right)$ is about 35-50 hours and is consistent with once-daily dosing. Amlodipine is extensively metabolized by the liver to inactive metabolites with $10 \%$ of the parent compound and $60 \%$ of metabolites excreted in the urine [2-4]. The most commonly reported adverse events (AEs) in patients treated with amlodipine are somnolence, dizziness, headache, palpitations, flushing, abdominal pain, nausea, oedema, and fatigue [5].

Oral administration of medication is reliant on the patient's ability to safely swallow the dosage form and can be problematic for individuals who have difficulty swallowing solid oral formulations. Epidemiologic studies indicate that the prevalence of dysphasia may be as high as $22 \%$ in those $>50$ years of age [6]. There is, therefore, considerable interest in providing patients with an alternative dosage form of amlodipine besides conventional tablets and capsules.

An orally disintegrating tablet (ODT) formulation of amlodipine has recently been developed. The ODT formulation was a mannitol based formulation with some flavouring and a colouring agent. The ODT tablets disperse rapidly when placed in the mouth and allow the constituents to be swallowed easily. It is desirable for prescribers to have the option of alternative oral dosing forms that are easier for patients to swallow and, in this respect; rapidly disintegrating ODTs offer administration benefit and convenience for patients. Additionally, amlodipine ODT would provide a convenient and discreet method for administration and would benefit patients who have a restriction on daily fluid intake, as it eliminates the need for administration with fluids.

*Corresponding author: Vincent Mascoli, Pfizer Inc., 235 East 42 ${ }^{\text {nd }}$ Street, New York 10017, USA, Tel: 212-573-1358; E-mail: vincent.mascoli@pfizer.com

Received December 14, 2012; Accepted January 16, 2013; Published January 22, 2013

Citation: Mascoli V, Kuruganti U, Bapuji AT, Wang R, Damle B (2013) Pharmacokinetics of a Novel Orodispersible Tablet of Amlodipine in Healthy Subjects. J Bioequiv Availab 5: 076-079. doi:10.4172/jbb.1000138

Copyright: $\odot 2013$ Mascoli V, et al. This is an open-access article distributed under the terms of the Creative Commons Attribution License, which permits unrestricted use, distribution, and reproduction in any medium, provided the original author and source are credited. 
This paper describes the two pivotal bioequivalence studies one comparing the ODT to the commercial tablet formulation, the other comparing the ODT to the commercial capsule formulation - conducted to support the registration of the amlodipine ODT formulation. The studies were done at amlodipine ODT $10 \mathrm{mg}$ which is the highest manufactured strength of the ODT formulation.

\section{Methods}

\section{Study design}

Two separate bioequivalence studies were performed; one comparing amlodipine ODT formulation versus commercial amlodipine tablets (NORVASC ${ }^{\circledR}$, Pfizer Inc., 235 East $42^{\text {nd }}$ Street, New York, NY 10017, USA), and the other comparing amlodipine ODT formulation versus commercial amlodipine capsules (NORVASC ${ }^{\circledR}$, Pfizer Inc., 235 East $42^{\text {nd }}$ Street, New York, NY 10017, USA). Each pivotal bioequivalence study was a randomized, open label, three-treatment, three-period, crossover, single-dose study in healthy subjects. Thirtysix subjects were enrolled into each of the two studies and-each-received the three treatments following one of the six treatment sequences that the subject was randomly assigned to $\mathrm{ABC}, \mathrm{ACB}, \mathrm{BCA}, \mathrm{BAC}, \mathrm{CBA}$, $\mathrm{CAB}$, where (A either amlodipine $10 \mathrm{mg}$ tablet or amlodipine $10 \mathrm{mg}$ capsule, administered with $240 \mathrm{ml}$ water under fasted conditions (Reference); (B)=amlodipine ODT $10 \mathrm{mg}$ without water under fasted conditions; and $(\mathrm{C})=$ amlodipine ODT $10 \mathrm{mg}$ with water under fasted conditions, where subjects were asked to allow the tablet to disintegrate completely in their mouth prior to drinking $240 \mathrm{ml}$ of water).

For ODT treatments in both studies, subjects were allowed to wet the mouth by swallowing $20 \mathrm{ml}$ of water directly before placing the ODT on the tongue. Subjects were required to place the ODT on the tongue for 30 seconds without crushing or breaking the tablet with their teeth. Water was allowed to be consumed without restriction beginning 2 hours post-dose.

In both studies, serial blood samples $(6 \mathrm{ml}$ each) were collected in tubes containing K2-EDTA during each period at the following time points: pre-dose and at $1,2,3,4,6,8,10,12,14,16,24,36,48,72,96,120$, and 168 hours post-dose. Plasma samples were analyzed for amlodipine. Safety was monitored by assessing AEs, laboratory test results, vital signs (pulse rate and blood pressure), and electrocardiograms (ECGs).

\section{Study population}

Subjects eligible to participate in both studies were healthy male or female subjects between the ages of 18 and 55 years. Subjects were required to have a body mass index (BMI) of $17.5-26.4 \mathrm{~kg} / \mathrm{m}^{2}$ and a total body weight $>50 \mathrm{~kg}$. Healthy subjects were defined as having no clinically relevant abnormalities identified by a detailed medical history, full physical examination, 12-lead ECG, and clinical laboratory tests. Inclusion criteria also required subjects to have a haemoglobin level of $\geq 13 \mathrm{gm} / \mathrm{dL}$. Subjects provided written informed consent prior to any study-related procedures.

All the studies were conducted at Axis Clinicals, a subsidiary of Aurobindo Pharma Ltd., located in Hyderabad, India. These studies were conducted in compliance with the ethical principles originating in or derived from the Declaration of Helsinki and in compliance with all International Conference on Harmonization Good Clinical Practice Guidelines. Written approval for both protocols and informed consent documents from Protection Plus (Institutional Review Board, Hyderabad, India) was obtained on January 21, 2011. In addition, all local regulatory requirements were followed.

\section{Pharmacokinetic analysis}

Pharmacokinetic blood samples were centrifuged at approximately 2500 relative centrifugal force (RCF) for 10 minutes at $4^{\circ} \mathrm{C}$. The plasma was stored in appropriately labeled vials at $-70^{\circ} \mathrm{C}$ within 1 hour of collection. Bioanalytical assays were conducted at Axis Clinicals, Hyderabad, India. Amlodipine samples were assayed using a validated, sensitive, and specific high-performance liquid chromatography tandem mass spectrometric method. Calibration standard responses were linear over the range of $0.050-10 \mathrm{ng} / \mathrm{ml}$. The lower limit of quantification for amlodipine was $0.050 \mathrm{ng} / \mathrm{ml}$. For the amlodipine assay, the accuracy (percent difference from nominal) of the quality control samples used during sample analysis ranged from 3.8-4.6\% in the amlodipine tablets bioequivalence study and $6.1-10.9 \%$ in the amlodipine capsules bioequivalence study.

The pharmacokinetics of amlodipine was determined by standard non-compartmental methods using WinNonlin version 5.0.1 (Pharsight Corporation, USA). Maximum plasma concentration $\left(\mathrm{C}_{\max }\right)$ and time for $\mathrm{C}_{\max }\left(\mathrm{T}_{\max }\right)$ were determined based on observed data. Area under the concentration versus time curve to the last quantifiable time point $\left(\mathrm{AUC}_{\text {last }}\right)$ was determined using the linear-log trapezoidal method. The elimination rate constant $(\lambda z)$ was estimated by linear regression of the linear portion of the log concentration versus time curve. The extrapolated total area under the concentration versus time curve to time infinity ( $\mathrm{AUC}_{\infty}$ ) was calculated as the sum of $\mathrm{AUC}_{0-\text { as }}$ and last observed concentration $/ \lambda z$. The $t_{1 / 2}$ was calculated as $\ln (2) / \lambda z$.

\section{Statistical analysis}

For both pivotal bioequivalence studies, natural log transformed AUC $_{\infty}$ (if data permit), $\mathrm{AUC}_{\text {last }}$, and $\mathrm{C}_{\max }$ were analyzed using a mixedeffect model with sequence, period, and treatment as fixed effects and subject within sequence as a random effect. Estimates of the adjusted mean differences (Test-Reference) and corresponding 90\% confidence intervals (CIs) were obtained from the model. The adjusted mean differences and $90 \%$ CIs for the differences were exponentiated to provide estimates of the ratio of adjusted geometric means (Test/ Reference) and 90\% CIs for the ratios.

Bioequivalence of Test treatment (amlodipine ODT with or without water) relative to the Reference treatment (commercial amlodipine tablet or capsule) would be concluded if the 90\% CI for the ratio of adjusted geometric means for both $\mathrm{AUC}_{\text {last }}$ and $\mathrm{C}_{\max }$ fell wholly within $(80 \%, 125 \%)$. The pharmacokinetic parameters $\mathrm{AUC}_{\text {mast }}, \mathrm{AUC}_{\infty}$ $\mathrm{C}_{\max }, \mathrm{T}_{\max }$, and $\mathrm{t}_{1 / 2}$ were summarized descriptively by treatment in each bioequivalence study.

\section{Results}

\section{Study populations}

In the ODT versus the tablet bioequivalence study, 36 subjects were enrolled and 18 subjects initially completed the study. The relatively high number of initial dropouts was because of the lack of subjects returning to the clinical research unit due to a local public holiday. As the number of completed subjects fell below the estimated sample size required to provide the desired power, an additional cohort of 18 subjects was added, as per protocol. A total of 35 subjects completed all three periods of the study, and 36 subjects completed at least one Test treatment and the Reference treatment. The mean age of the subjects was 29.0 years (range, 18.0-46.0 years) and the mean BMI was $21.2 \mathrm{~kg} / \mathrm{m}^{2}$ (range $18.5-25.0$ $\left.\mathrm{kg} / \mathrm{m}^{2}\right)$.

In the ODT versus the capsule bioequivalence study, 36 subjects were enrolled and 32 subjects completed the study. Of the four noncompleters, one subject was withdrawn from the study due to the 
AE of vomiting, which resolved on follow-up without any additional medication, and the remaining three withdrew for personal reasons. The mean age was of subjects was 27.6 years (range, 19.0-41.0 years) and the mean BMI was $21.8 \mathrm{~kg} / \mathrm{m}^{2}$ (range, $18.2-25.0 \mathrm{~kg} / \mathrm{m}^{2}$ ).

\section{Pivotal bioequivalence studies}

ODT versus tablet study: The mean concentration-time profiles for amlodipine ODT versus tablet are shown in (Figure 1). The mean amlodipine plasma concentration-time profiles for all three treatments were essentially overlapping. The corresponding pharmacokinetic parameters are provided in (Table 1). Systemic exposure $\left(\mathrm{C}_{\max }\right.$ and AUC) of amlodipine was comparable across the three treatments. Median $\mathrm{T}_{\max }$ values were also comparable across all treatments with a median $\mathrm{T}_{\max }^{\max }$ of 8.00 hours. Mean terminal $\mathrm{t}_{1 / 2}$ was approximately 58 hours for all treatments. The variability for $\mathrm{C}_{\max }$ and $\mathrm{AUC}_{\text {last }}$, based on percent coefficient of variation, was generally similar for all treatments (18-28\%). The protocol-specified bioequivalence criteria were met for amlodipine ODT given without water relative to amlodipine tablet as the $90 \%$ CIs for the adjusted geometric mean ratio of amlodipine $\mathrm{C}_{\max }$ $\mathrm{AUC}_{\infty}$, and $\mathrm{AUC}_{\text {lat }}$ were entirely contained within the equivalence interval of $80-125 \%$ (Table 1). When a mlodipine ODT was given with water, the $90 \%$ CIs for the adjusted geometric mean ratio of amlodipine $\mathrm{AUC}_{\infty}, \mathrm{AUC}_{\text {last }}$, and $\mathrm{C}_{\max }$ were entirely contained within the $80-125 \%$ interval.

ODT versus capsule study: The mean concentration-time profiles for amlodipine ODT versus capsule are shown in (Figure 2). The mean amlodipine plasma concentration-time profiles for all three treatments were essentially overlapping. The corresponding pharmacokinetic parameters are provided in (Table 2). Systemic exposure $\left(\mathrm{C}_{\max }\right.$ and AUC) of amlodipine was comparable across the three treatments. Median $\mathrm{T}_{\max }$ values were also comparable across all treatments (Table 2). Mean terminal $t_{1 / 2}$ was approximately 54 hours for all treatments. The variability for $\mathrm{AUC}_{\text {last }}$, and $\mathrm{C}_{\max }$, based on percent coefficient of variation, was generally similar for all treatments (24-33\%). The protocol-specified bioequivalence criteria were met for amlodipine ODT given without water relative to amlodipine tablet as the $90 \% \mathrm{CIs}$ for the adjusted geometric mean ratio of amlodipine $\mathrm{AUC}_{\infty}, \mathrm{AUC}_{\text {last' }}$ and $\mathrm{C}_{\max }$ were entirely contained within the equivalence interval of $80-125 \%$ (Table 2). When a mlodipine ODT was given with water, the $90 \%$ CIs for the adjusted geometric mean ratio of amlodipine AUC, $\mathrm{AUC}_{\text {last }}$, and $\mathrm{C}_{\max }$ were entirely contained within the $80-125 \%$ interval.

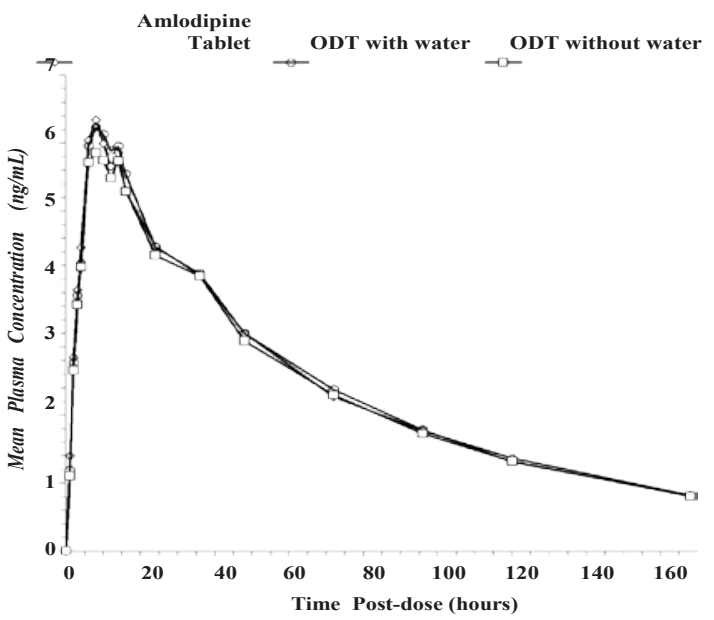

Figure 1: Mean plasma concentration-time profile for amlodipine following administration of $10 \mathrm{mg}$ dose amlodipine tablet and ODT given with or without water in the pivotal bioequivalence study.

\begin{tabular}{|c|c|c|c|}
\hline Parameter (Units) & $\begin{array}{l}\text { Amlodipine } \\
\text { Tablet (With } \\
\text { Water, } n=35 \text { ) }\end{array}$ & $\begin{array}{c}\text { Amlodipine ODT } \\
\text { (Without Water, } \\
\quad n=36)\end{array}$ & $\begin{array}{c}\text { Amlodipine ODT } \\
\text { (With Water, } \\
n=35)\end{array}$ \\
\hline $\operatorname{AUC}_{\infty}\left(\mathrm{ng}^{\star} \mathrm{hr} / \mathrm{mL}\right)$ & $498.6(133.0)$ & $481.4(162.3)$ & $495.9(149.7)$ \\
\hline Ratio $(90 \% \mathrm{Cl})^{*}$ & & $\begin{array}{c}95.88 \\
(90.47,101.61)\end{array}$ & $\begin{array}{c}98.79 \\
(93.21,104.70)\end{array}$ \\
\hline $\mathrm{AUC}_{\text {last }}\left(\mathrm{ng} \mathrm{g}^{*} \mathrm{hr} / \mathrm{mL}\right)$ & $420.3(97.1)$ & $404.5(111.3)$ & $423.0(111.1)$ \\
\hline Ratio $(90 \% \mathrm{Cl})^{*}$ & & $\begin{array}{c}96.10 \\
(90.98,101.52)\end{array}$ & $\begin{array}{c}100.09 \\
(94.74,105.74)\end{array}$ \\
\hline $\mathrm{C}_{\max }(\mathrm{ng} / \mathrm{mL})$ & $6.7(1.2)$ & $6.4(1.3)$ & $6.8(1.6)$ \\
\hline Ratio $(90 \% \mathrm{Cl})^{\star}$ & & $\begin{array}{c}95.14 \\
(90.44,100.08)\end{array}$ & $\begin{array}{c}100.23 \\
(95.27,105.45)\end{array}$ \\
\hline $\mathrm{T}_{\max }(\mathrm{h})$ & $8.0(3.0-16.0)$ & $8.0(6.0-14.0)$ & $8.0(2.0-16.0)$ \\
\hline$t_{1 / 2}(h)$ & $61.5(18.7)$ & $57.6(19.2)$ & $58.2(11.6)$ \\
\hline
\end{tabular}

Arithmetic mean (standard deviation) for all except median (range) for $\mathrm{T}_{\max }$

"Ratio of adjusted geometric means $(90 \% \mathrm{Cl}$ ) for Test (amlodipine ODT with or without water) versus Reference (amlodipine tablet with water) treatment.

Table 1: Summary of pharmacokinetic parameters in the pivotal bioequivalence study of amlodipine ODT versus amlodipine tablets.

\section{Discussion}

Amlodipine ODT has been developed to provide an alternate dosage form for patients who have difficulty swallowing. These ODT tablets disperse rapidly when placed in the mouth, thereby allowing the constituents to be swallowed more easily and without the necessity of concomitant administration with water. These bioequivalence studies demonstrate that amlodipine ODT given with and without water is bioequivalent with respect to both $\mathrm{C}_{\max }$ and AUC relative to the currently marketed amlodipine tablet and capsule. Amlodipine ODT formulation can therefore be considered clinically interchangeable with NORVASC ${ }^{\circledR}$ (Pfizer Inc., 235 East $42^{\text {nd }}$ Street, New York, NY 10017, USA) tablets and capsules.

The pharmacokinetic data in these studies also suggest that the absorption characteristics of amlodipine are not different between ODT and the currently available commercial tablets and capsules, and that significant buccal absorption of amlodipine is unlikely to occur with the ODT formulation. Buccal absorption of any compound is characterized by changes in the systemic bioavailability of the drug due to bypassing first pass metabolism [7]. Amlodipine is mainly metabolized by CYP3A4 and the metabolites are pharmacologically inactive [8]. When administered orally, amlodipine has an absolute bioavailability of $64 \%$ [9]. Therefore, if significant buccal absorption of amlodipine did occur following administration of the ODT formulation, it would be expected to bypass the first pass metabolism and increase the bioavailability compared with the Reference formulation. The median $\mathrm{T}_{\text {max }}$ value for amlodipine following administration of the ODT in both studies was approximately 6 or 8 hours, and was consistent with those seen for the commercial tablet or capsule. Furthermore, the physicochemical properties of a drug also impacts buccal absorption. The ODT tablets are formulated to disintegrate very rapidly (within 30 seconds) upon contact with saliva when placed on the tongue. Contact time of the disintegrated tablet, whether administered with or without water, is limited ( $<1$ minute), which is not conducive for buccal absorption. Ionization state of a compound also plays a factor in buccal absorption since only the non-ionized form is absorbed. Amlodipine is a weak base with a pKa value of about 8.6 at $25^{\circ} \mathrm{C}[10]$. As the average $\mathrm{pH}$ in the mouth is about 6.5, any dissolved amlodipine will be in an ionized state. Notably, amlodipine is only slightly soluble in water $[11,12]$. The experimental water solubility for amlodipine is $75.3 \mathrm{mg} / \mathrm{L}$ [10]. The lowest solubility in the $\mathrm{pH}$ range from $1-6.8$ at $37^{\circ} \mathrm{C}$ is $1 \mathrm{mg} / \mathrm{ml}$ [13]. If any dissolution of amlodipine occurs in the mouth following administration of ODT, the resultant compound would be in an ionized form, which would not be absorbed via passive diffusion 
Citation: Mascoli V, Kuruganti U, Bapuji AT, Wang R, Damle B (2013) Pharmacokinetics of a Novel Orodispersible Tablet of Amlodipine in Healthy Subjects. J Bioequiv Availab 5: 076-079. doi:10.4172/jbb.1000138

in the buccal cavity. It can be concluded that amlodipine ODT is not absorbed from the buccal cavity but, that after disintegrating in the mouth and being swallowed, the drug undergoes absorption further down the gastrointestinal track similar to that of the commercial capsules and tablets.

In addition to amlodipine ODT $10 \mathrm{mg}, 5 \mathrm{mg}$ ODT strength is also under development. It should be noted that amlodipine pharmacokinetics are linear up to $10 \mathrm{mg}$ dose. The 5 and $10 \mathrm{mg}$ ODT formulations are manufactured from a proportional blend using similar equipment and methods. Furthermore, the in-vitro dissolution profile between 5 and $10 \mathrm{mg}$ ODT has been demonstrated to be similar (no f2 test was performed since more than $85 \%$ of the drug was released within 15 minutes in all media tested). Considering these, the bioequivalence results from amlodipine ODT $10 \mathrm{mg}$ can be extrapolated to $5 \mathrm{mg}$ strength.

\begin{tabular}{|c|c|c|c|}
\hline Parameter (Units) & $\begin{array}{l}\text { Amlodipine } \\
\text { Capsule (with } \\
\text { Water, } n=35 \text { ) }\end{array}$ & $\begin{array}{c}\text { Amlodipine ODT } \\
\text { (Without Water, } \\
n=35 \text { ) }\end{array}$ & $\begin{array}{c}\text { Amlodipine ODT } \\
\text { (With Water, } \\
n=33)\end{array}$ \\
\hline $\mathrm{AUC}_{\infty}\left(\mathrm{ng}{ }^{*} \mathrm{hr} / \mathrm{mL}\right)$ & $433.8(155.7)$ & $424.1(123.4)$ & $442.8(119.3)$ \\
\hline Ratio $(90 \% \mathrm{Cl})^{*}$ & & $\begin{array}{c}97.89 \\
(92.75,103.32)\end{array}$ & $\begin{array}{c}102.74 \\
(97.27,108.51)\end{array}$ \\
\hline $\mathrm{AUC}_{\text {last }}\left(\mathrm{ng}^{*} \mathrm{hr} / \mathrm{mL}\right)$ & $372.0(123.8)$ & $368.3(102.6)$ & $385.0(97.7)$ \\
\hline Ratio $(90 \% \mathrm{Cl})^{*}$ & & $\begin{array}{c}100.42 \\
(92.81,108.66)\end{array}$ & $\begin{array}{c}105.55 \\
(97.44,114.33)\end{array}$ \\
\hline $\mathrm{C}_{\max }(\mathrm{ng} / \mathrm{mL})$ & $6.3(1.5)$ & $5.7(1.4)$ & $5.9(1.5)$ \\
\hline Ratio $(90 \% \mathrm{Cl})^{*}$ & & $\begin{array}{c}89.94 \\
(86.32,93.71)\end{array}$ & $\begin{array}{c}94.09 \\
(90.26,98.08)\end{array}$ \\
\hline $\mathrm{T}_{\max }(\mathrm{h})$ & $6.0(2.0-12.0)$ & $8.0(2.0-16.0)$ & $6.0(4.0-16.0)$ \\
\hline$t_{1 / 2}(h)$ & $53.9(15.5)$ & $55.7(11.0)$ & $54.5(9.9)$ \\
\hline
\end{tabular}

Arithmetic (standard deviation) for all except median (range) for $\mathrm{T}_{\max }$.

"Ratio of adjusted geometric mean $(90 \% \mathrm{Cl})$ for Test (amlodipine ODT with or without water) versus Reference (amlodipine capsule with water) treatment.

Table 2: Summary of pharmacokinetic parameters in the pivotal bioequivalence study of amlodipine ODT versus amlodipine capsules.

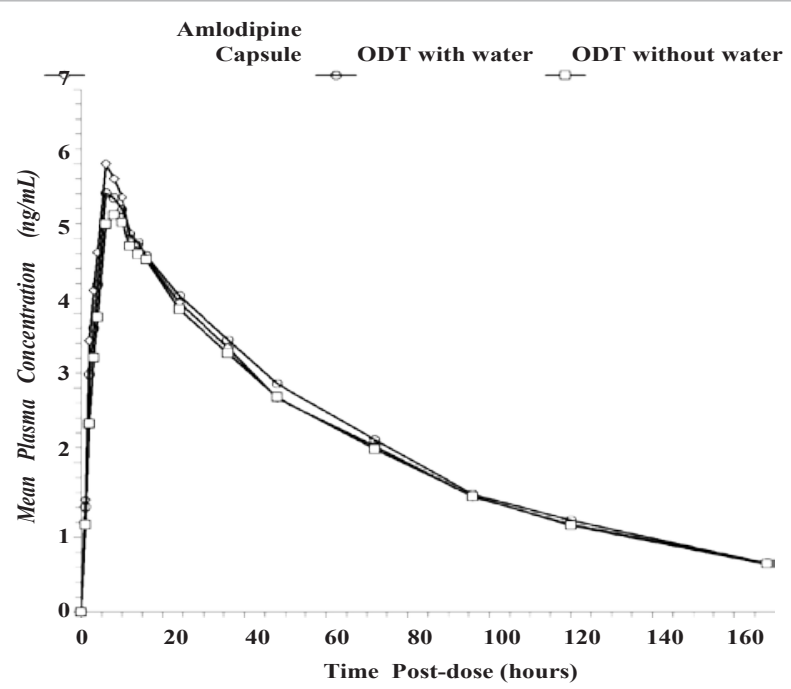

Figure 2: Mean plasma concentration-time profile for amlodipine following administration of $10 \mathrm{mg}$ dose amlodipine capsule and ODT given with or without water in the pivotal bioequivalence study.
In summary, amlodipine has been available for many years for the treatment of a variety of cardiac indications. Its safety and efficacy are well established. In addition to the presently marketed amlodipine tablets and capsules, the novel ODT formulation of amlodipine offers an option for patients who have difficulty swallowing, and offers a convenient and discreet method of administration without the need for water.

\section{Acknowledgments}

This study was sponsored by Pfizer Inc. Vincent Mascoli, Uma Kuruganti, Rong Wang and Bharat Damle is an employee of Pfizer Inc. A.T. Bapuji is an employee of Aurobindo Pharma Ltd who were paid consultants to Pfizer in connection with the study and the development of this manuscript. Editorial support was provided by Abegale Templar, PhD and Helen Jones, PhD of UBC Scientific Solutions and funded by Pfizer Inc.

\section{References}

1. Burges RA, Gardiner DG, Gwilt M, Higgins AJ, Blackburn KJ, et al. (1987) Calcium channel blocking properties of amlodipine in vascular smooth muscle and cardiac muscle in vitro: evidence for voltage modulation of vascular dihydropyridine receptors. J Cardiovasc Pharmacol 9: 110-119.

2. Stopher DA, Beresford AP, Macrae PV, Humphrey MJ (1988) The metabolism and pharmacokinetics of amlodipine in humans and animals. J Cardiovasc Pharmacol 12: S55-D59.

3. Faulkner JK, McGibney D, Chasseaud LF, Perry JL, Taylor IW (1986) The pharmacokinetics of amlodipine in healthy volunteers after single intravenous and oral doses and after 14 repeated oral doses given once daily. $\mathrm{Br} \mathrm{J} \mathrm{Clin}$ Pharmacol 22: 21-25.

4. Data on file. Pfizer Inc.

5. Data on file. Pfizer Inc.

6. Howden, CW (2004) Management of acid-related disorders in patients with dysphagia. Am J Med 117: 44S-48S.

7. Pond SM, Tozer TN (1984) First-pass elimination. Basic concepts and clinica consequences. Clin Pharmacokinet 9: 1-25.

8. Beresford AP, McGibney D, Humphrey MJ, Macrae PV, Stopher DA (1988) Metabolism and kinetics of amlodipine in man. Xenobiotica 18: 245-254.

9. Abernethy DR (1989) The pharmacokinetic profile of amlodipine. Am Heart $J$ 118: 1100-1103.

10. Drug Bank open data drug \& drug target database. Drug card for amlodipine.

11. United States Pharmacopeia and National Formulary USP 29-NF (2006) The United Pharmacopeial Convention.

12. European Directorate for the Quality of Medicines, Council of Europe (2007) European Pharmacopeia (6thedn); Strasbourg, France.

13. WHO Expert Committee on Specifications for Pharmaceutical Preparations (2006) WHO Technical Report Series, no. 937, Annex 8. Proposal to waive in vivo bioequivalence requirements for WHO Model List of Essential Medicines immediate release, solid oral dosage forms; World Health Organization: Geneva, Switzerland. 